\title{
Relationship of Sahel Precipitation and Atmospheric Centers of Action
}

\author{
Sultan Hameed ${ }^{1}$ and Nicole Riemer ${ }^{2}$ \\ ${ }^{1}$ School for Marine and Atmospheric Sciences, Stony Brook University, Stony Brook, NY 11794-5000, USA \\ ${ }^{2}$ Department of Atmospheric Sciences, University of Illinois, Urbana, IL 61801, USA
}

Correspondence should be addressed to Sultan Hameed, sultan.hameed@stonybrook.edu

Received 4 May 2012; Accepted 6 September 2012

Academic Editor: Youmin Tang

Copyright ( $) 2012$ S. Hameed and N. Riemer. This is an open access article distributed under the Creative Commons Attribution License, which permits unrestricted use, distribution, and reproduction in any medium, provided the original work is properly cited.

\begin{abstract}
The dynamics associated with drought in the Sahel have attracted considerable attention in the recent literature. This paper evaluates Sahel precipitation using the paradigm of the atmospheric centers of action, that is, the extended semipermanent highs and lows that dominate regional circulations and are evident in sea level pressure patterns. We find that Sahel precipitation is significantly influenced by changes in the Azores High and the South Asia Low. Specifically, about 50 percent of the variance of July to September rainfall over the Sahel is explained by changes in the Azores High Longitude position and South Asia Low pressure. In contrast, the contribution of the Southern Oscillation to Sahel precipitation is smaller in comparison. Results presented in this paper suggest that a key test for a climate model in simulating variability of Sahel rainfall is the accuracy with which the model simulates the dynamics of South Asia Low and the Azores High.
\end{abstract}

\section{Introduction}

Since the 1950s, the semiarid African Sahel zone has undergone a persistent drought, although there is some amelioration observed since the 1980s. Several theories on the cause of this phenomenon have been discussed, with a final conclusion and a quantification of human versus natural causes still to be reached. The Sahel drought does not only have devastating consequences for the Sahel region itself [1], but it also influences regions far away because of the increased output of soil-derived aerosol particles into the atmosphere $[2,3]$.

Soon after the drought in Sahel became known as a major climatic phenomenon, Angell and Korshover [4] analyzed the trends in the atmospheric centers of action and suggested that "the southward or southeastward movement of the Azores High after 1945 is related to the recent drought just south of the Sahara (Sahelian Zone)." Later other more local processes were put forth as influencing Sahel rainfall such as changes in albedo due to land use change [5], the amount of moisture in the soil [6], and the surface roughness [7]. These can be influenced by overgrazing or deforestation, which led to the hypothesis that human activity contributes to the continuing drought by impacting the land surface processes, and which in turn affect atmospheric circulation.

More recently, several global climate models have been used to study Sahel precipitation by using the paradigm that the Sahel rainfall responds to sea surface temperature changes in certain ocean basins $[8,9]$. Some models have been used to make projections for Sahel precipitation in the future under global warming scenarios. It turns out that different global models can give reasonable simulations of the variations of Sahel precipitation in the 20th century but yield differing projections for the 21st century. Cook and Vizy [9] examined some of the processes related to Sahel precipitation in IPCC's AR4 global climate models (GCMs). They screened eighteen AR4 coupled GCMs using the climatology of Sahel precipitation and its response to sea surface temperature (SST) anomalies in the Gulf of Guinea. Three of the GCMs were found satisfactory in terms of these criteria but they generated contradictory projections for Sahel precipitation in the 21st century. Tippett [10] investigated seven coupled GCM simulations of Sahel precipitation and traced their difficulty in reproducing the interannual variability to poor representation of physical processes (especially convection) and neglect feedback of the atmosphere to the ocean. 
Considering the challenges that GCMs face in capturing the variability of Sahel precipitation, in this study we elucidate the governing mechanisms with a different approach. The rationale for this is as follows. In terms of basic meteorological processes, precipitation occurs over the Sahel when the lower atmosphere is unstable and clouds are present over the region. A satisfactory mechanism for explaining variations in Sahel precipitation must include variations in atmospheric stability and cloud cover over the Sahel. A direct indication of changes in stability and cloud cover is given by changes in the distribution of pressure in the lower atmosphere. In an early paper Angell and Korshover [4] made the observation that the displacement of the Azores High pressure system affects Sahel rainfall, and its southeastward shift may be responsible for the drought. Using the more complete gridded surface level pressure (SLP) data now available from NCEP/NCAR reanalysis we examine for this study changes in atmospheric pressure in the region around the Sahel. We use the "Centers of Action" approach first introduced by Rossby et al. [11]. Figure 1 shows the distribution of July-August-September SLP averaged for 1975-2005 for the region around the Sahel. We see the dominating presence of two atmospheric centers of action: the Azores High to the west, characterized by SLP > $1020 \mathrm{hPa}$ in its center over the north Atlantic, and the South Asia Low to the east, in which SLP $\approx 1000 \mathrm{hPa}$ extends from eastern Saudi Arabia to north India. It is interesting to note that the outer contour of the South Asia Low extends into the Sahel region. We therefore focus on the variations of these pressure centers and their influence on precipitation over Sahel.

For this study we calculate objective indices of the monthly averaged pressures and locations of these centers as described in Section 2. Section 3 shows that the longitudinal movement of the Azores High and the intensity of the South Asia Low are significantly correlated with Sahel rainfall. With a composite analysis we investigate the underlying physical mechanisms for these relationships. Section 4 concludes our findings.

\section{The Atmospheric Centers of Action}

Rossby et al. [11] constructed atmospheric pressure charts for the northern hemisphere and upon averaging daily pressure values identified several large-scale structures they called the "semi-permanent centers of action." These included the Icelandic and Aleutian Lows, the Azores High, the Hawaiian High, and the Siberia High. They investigated the impact of the longitudinal displacement of the Aleutian Low on the circulation in the North Pacific, thus introducing the concept that the movements of the atmospheric pressure centers can be used as indicators of regional circulation changes. This concept has been successfully applied to explain the variability in many geophysical systems $[2,3,12]$ and will also prove useful in the present investigation, where we will see that the longitudinal displacements of the Azores High pressure center significantly impact circulation over North Africa, and therefore, precipitation amounts over the Sahel region.
In order to quantify the changes in the centers of action, objective indices for the pressure, latitude, and longitude locations for the centers can be calculated using gridded SLP data as described by Hameed et al. [13]. By examining the monthly SLP maps of the past one hundred years, the latitude-longitude domains over which each of the pressure centers occurs were identified. The pressure index is then defined as an area-weighted pressure departure from a threshold value over the domain $(I, J)$ :

$$
I_{p}=\frac{\sum_{i j=1}^{I J}\left(P_{i j}-P_{t}\right) \cos \phi_{i j}(-1)^{M} \delta_{i j}}{\sum_{i j=1}^{I J} \cos \phi_{i j} \delta_{i j}},
$$

where $P_{i j}$ is the SLP value at grid point $(i, j), P_{t}$ is the threshold SLP value $\left(P_{t}=1014 \mathrm{hPa}\right.$ for Azores High and $1013 \mathrm{hpa}$ for South Asia Low), and $\phi_{i j}$ is the latitude of grid point $(i, j) . M=0$ for the Azores High and 1 for the South Asia Low. $\delta=1$ if $(-1)^{M}\left(P_{i j}-P_{t}\right)>0$ and $\delta=0$ if $(-1)^{M}\left(P_{i j}-P_{t}\right)<0$. The pressure index is thus a measure of the anomaly of atmospheric mass over the study sector $(I, J)$. The latitudinal index is defined as

$$
I_{\phi}=\frac{\sum_{i j=1}^{I J}\left(P_{i j}-P_{t}\right) \phi_{i j} \cos \phi_{i j}(-1)^{M} \delta_{i j}}{\sum_{i j=1}^{I J}\left(P_{i j}-P_{t}\right) \cos \phi_{i j}(-1)^{M} \delta_{i j}}
$$

and the longitudinal index $I_{\lambda}$ is defined in an analogous manner. The location indices thus give pressure-weighted mean latitudinal and longitudinal positions of the centers.

Monthly indices of the pressure, latitude, and longitude for these centers were calculated according to (1) and (2). The area domains used in this calculation are $\left(10^{\circ} \mathrm{N}-35^{\circ} \mathrm{N}, 35^{\circ} \mathrm{E}-\right.$ $\left.95^{\circ} \mathrm{E}\right)$ for the South Asia Low and $\left(20^{\circ} \mathrm{N}-50^{\circ} \mathrm{N}, 70^{\circ} \mathrm{W}-10^{\circ} \mathrm{E}\right)$ for the Azores High. Although gridded monthly SLP data for the northern hemisphere from 1899 is available from NCAR [14], there are many data gaps over the South Asia region before 1950, and the indices for the South Asia Low could not be calculated for the first half of the 20th century. For this reason, indices used in this paper were calculated using monthly SLP data from National Centers for Environmental Prediction [15] which begin in 1948 and have a higher spatial resolution $\left(2.5^{\circ} \times 2.5^{\circ}\right)$ versus the $\left(4^{\circ} \times 5^{\circ}\right)$ for the NCAR data set.

For Sahel precipitation data we use the monthly mean rain gauge data set by Hulme et al. [16, 17]. This data set ("gu23wld0098.dat" (Version 1.0)) provides monthly global precipitation data over land gridded to a resolution of 2.5 degree latitude by 3.75 degree longitude for 1900-1998. Following previous studies $[18,19]$, we define Sahel as the region from $10^{\circ} \mathrm{N}-20^{\circ} \mathrm{N}$ and $20^{\circ} \mathrm{W}-35^{\circ} \mathrm{E}$. This region receives about $70 \%$ of the yearly rainfall during July, August, and September. Continuous estimates of sea level pressure are available in NCEP reanalysis since 1948 . Consequently we analyze Sahel precipitation for 1948-1998. 


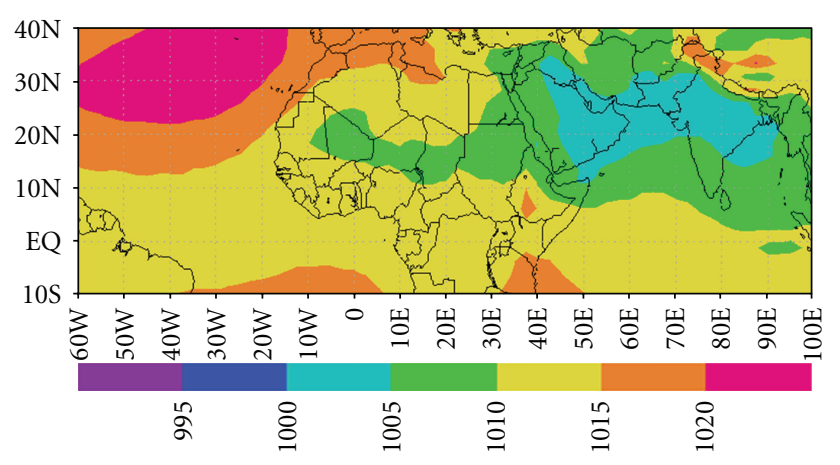

Figure 1: Average SLP for July, August, and September 1975-2005. Although the center of the SAL is situated over the region from the Arabian Peninsula eastward to northern India, its influence extends westward over the Sahara and the Sahel region.

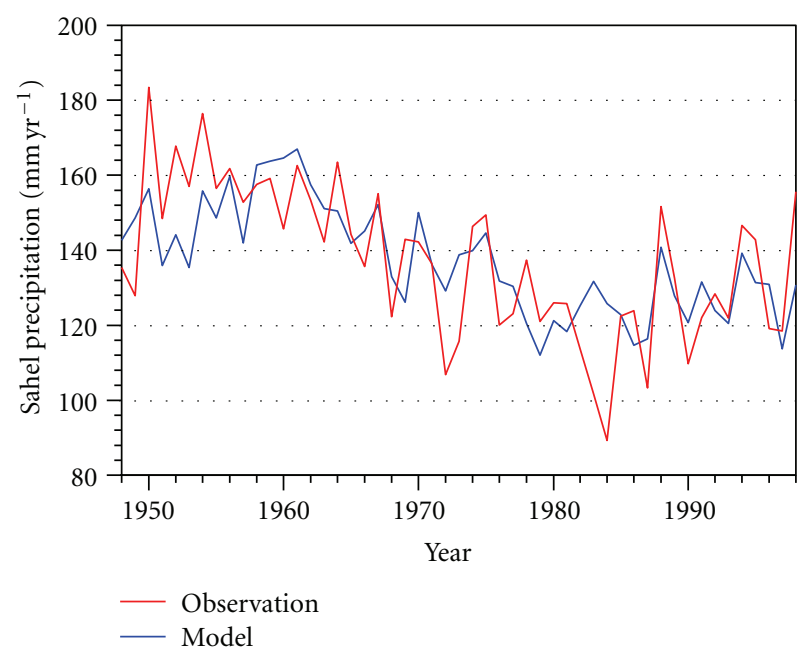

Figure 2: Sahel precipitation in $\mathrm{mm} \mathrm{yr}^{-1}$ : data and regression on the basis of SAL pressure and AZH longitude.

\section{Results}

3.1. Statistical Relationships of the COA and Sahel Precipitation. Interannual variations of precipitation over the Sahel during the rainy season July-August-September (JAS) are considered in this paper. As discussed above, the two atmospheric centers of action in the proximity of the Sahel region, and likely to influence the circulation over it, are the Azores High and the South Asia Low. Each center of action is characterized by fluctuations in its pressure, latitude position, and longitude position. We have therefore calculated correlations between the JAS averaged indices characterizing pressure, latitude, and longitude of each center of action with Sahel precipitation. The results are shown in Table 1. The correlations of Sahel precipitation and the SAL pressure $(-0.68)$ and the AZH longitude $(-0.41)$ are statistically significant at the 5 percent level. Because the South Asia Low and Sahel precipitation are highly autocorrelated, the effective sample sizes for their correlations are diminished, as shown in Table 1. For this reason the correlation with SAL latitude (0.44) is not statistically significant. The effective
TABLE 1: COA variable, corresponding correlation coefficient with Sahel precipitation, and effective sample size. Bold: value statistically significant at the 5\% level. The Azores High and South Asia data are for 1948-1998, and the SOI values are for 1951-1998.

\begin{tabular}{lcc}
\hline COA variable & $\begin{array}{c}\text { Correlation with Sahel } \\
\text { precipitation }\end{array}$ & $\begin{array}{c}\text { Effective sample } \\
\text { size }\end{array}$ \\
\hline SAL pressure & $-\mathbf{0 . 6 8}$ & 9 \\
SAL latitude & 0.44 & 10 \\
SAL longitude & 0.16 & 17 \\
AZH pressure & -0.17 & 29 \\
AZH latitude & -0.05 & 51 \\
AZH longitude & $-\mathbf{0 . 4 1}$ & 43 \\
SOI (1951-1998) & $\mathbf{0 . 3 4}$ & 48 \\
\hline
\end{tabular}

TABle 2: Columns 2 and 3 give the mean values and standard deviations of COA indices related to Sahel precipitation, and columns 4, 5, and 6 are their mutual correlations. The Azores High and South Asia data are for 1948-1998, and the SOI values are for 1951-1998.

\begin{tabular}{lccccc}
\hline COA & Mean & Std Dev & $\begin{array}{c}\text { AZH } \\
\text { longitude }\end{array}$ & $\begin{array}{c}\text { SAL } \\
\text { pressure }\end{array}$ & SOI \\
\hline AZH longitude & -36.2 & 1.3 & 1.0 & 0.20 & 0.025 \\
SAL pressure & $1005.1 \mathrm{mb}$ & $0.92 \mathrm{mb}$ & 0.20 & 1.0 & $-\mathbf{0 . 4 2}$ \\
SOI & -0.22 & 1.49 & 0.025 & $-\mathbf{0 . 4 2}$ & 1.0 \\
\hline
\end{tabular}

sample sizes were calculated using the procedure described in [20]. The correlations suggest that a deeper SAL, and a westward shift of the AZH, correspond to increased precipitation. Both of the correlations have clear physical significance. The SAL in late summer extends up to the Sahel region (Figure 1), therefore a year in which this system is deeper will contribute to a lower pressure over the Sahel which will contribute to increased rainfall. Similarly, when the AZH drifts to the west, away from Africa, lower pressure occurs in the lower atmosphere over the Sahel, which leads to enhanced precipitation.

3.1.1. Regression Analysis. From Table 1 we see that three atmospheric variables are significantly correlated with Sahel precipitation and could possibly be used as independent variables in a regression equation, SAL pressure, AZH longitude, and the Southern Oscillation Index (SOI). In order to check their independence from each other we calculated their mutual correlations, shown in Table 2.

The correlation between SAL pressure and SOI is statistically significant at the $5 \%$ level, and therefore they cannot be used in the same regression equation. The two possible regressions are as follows:

(I) SAL Pressure and AZH Longitude as independent

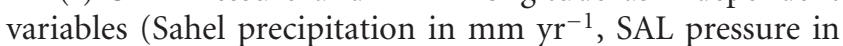
$\mathrm{hPa}$, and $\mathrm{AZH}$ longitude in degree):

\section{Sahel Precipitation}

$$
=13271-0.251 \mathrm{AZH} \text { longitude }-0.611 \mathrm{SAL} \text { pressure. }
$$




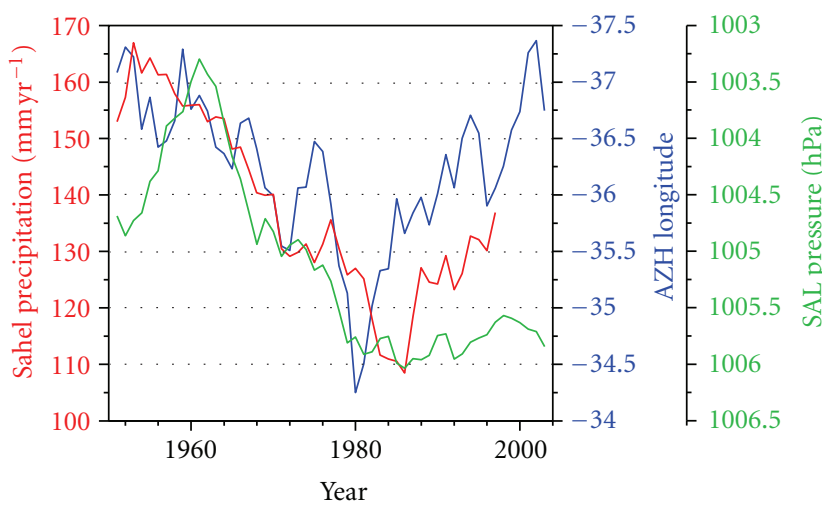

(a)

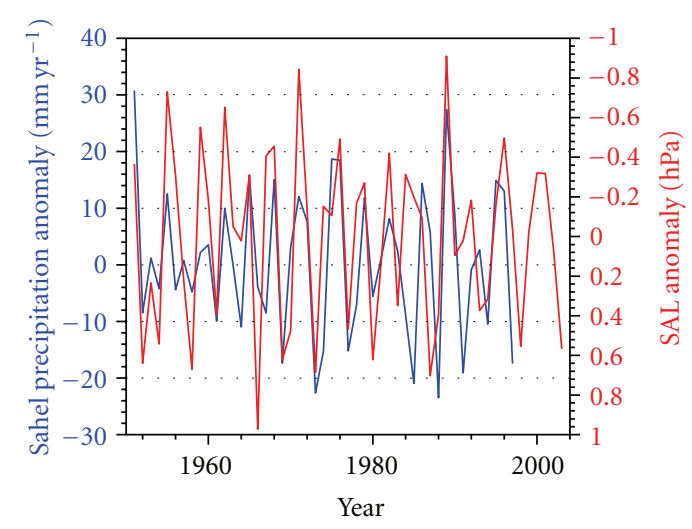

(b)

FIgURE 3: (a) 5-year moving averages: Sahel precipitation (red), AZH longitude (blue), and SAL pressure (green, its axis has been inverted in the figure to facilitate comparison with Sahel precipitation). (b) Sahel precipitation anomalies (blue) and SAL pressure anomalies (red).

For this regression $r=0.72$, and the standard error of estimate is 14.4. The partial correlation coefficients for the AZH longitude and the SAL pressure are -0.33 and -0.65 , respectively. The coefficients in (3) are for standardized independent variables (i.e., for mean 0 and standard deviation 1 ),

(II) SOI and AZH Longitude as independent variables:

the regression equation is

$$
\begin{aligned}
& \text { Sahel Precipitation } \\
& \qquad=-68.8-0.38 \mathrm{AZH} \text { longitude }+0.36 \mathrm{SOI} .
\end{aligned}
$$

For this regression $r=0.51$, and the standard error of estimate is 17.4 .

Equation (4) explains 26 percent of the precipitation variance while (3) explains 52 percent. The partial correlation coefficients for AZH longitude and the SOI are -0.38 and 0.36 , respectively.

\subsubsection{Relative Significance of ENSO and the South Asia Low.} Several studies have documented a relationship between ENSO and Sahel Precipitation [8, 18, 19]. Moreover, relationships between ENSO and atmospheric and ocean circulation in the South Asia region have been documented in several studies [21, chapter 12]. A question then arises as to the relevant significance of ENSO and South Asia Low to Sahel precipitation. Comparison of (3) and (4) shows that ENSO's impact on Sahel precipitation is overshadowed by that of the South Asia Low. This inference is supported also by the partial correlation analysis shown in Table 3 . The partial correlation between Sahel precipitation and SAL pressure is -0.66 when adjusted by SOI. However, the partial correlation between Sahel precipitation and SOI is only 0.09 when adjusted for SAL pressure.

3.2. Long-Term Trend and Interannual Variability of Sahel Precipitation. Precipitation values obtained from (3) are compared with observations in Figure 2. This statistical hindcast model correctly simulates the decline in precipitation up to the mid 1980s and its subsequent rise.
TABLE 3: Partial correlation analysis for the independent variables identified in Table 1.

\begin{tabular}{lcc}
\hline Correlating variables & $\begin{array}{c}\text { Adjusting } \\
\text { variable }\end{array}$ & $\begin{array}{c}\text { Partial correlation } \\
\text { coefficient }\end{array}$ \\
\hline $\begin{array}{l}\text { Sahel precipitation-SAL } \\
\text { Pressure }\end{array}$ & SOI & -0.66 \\
$\begin{array}{l}\text { Sahel precipitation-SAL } \\
\text { Pressure }\end{array}$ & AZH longitude & -0.65 \\
$\begin{array}{l}\text { Sahel precipitation-SOI } \\
\text { Sahel precipitation-SOI }\end{array}$ & SAL pressure & 0.09 \\
$\begin{array}{l}\text { Sahel precipitation-AZH } \\
\text { Longitude } \\
\text { Sahel precipitation-AZH } \\
\text { Longitude }\end{array}$ & SAL pressure & 0.38 \\
\hline
\end{tabular}

The Sahel precipitation in Figure 2 displays considerable interannual variability superimposed on the long-term trend. To separate the lower frequency trend from the shortterm variability we calculate 5-year moving averages of the Sahel precipitation and compare it with the 5-year moving averages of the AZH longitude and the SAL pressure in Figure 3(a). The correlations of the smoothed time series are (Sahel, SAL: $r=-0.86$ ), and (Sahel, AZH: $r=$ -0.71 ), both being marginally significant at $5 \%$ after taking autocorrelation into account. In Figure 3(a) we see that the AZH shifted persistently eastward in the earlier part of the record with a parallel decrease in Sahel precipitation. The AZH switched direction and has been migrating westward since about 1981, and the Sahel precipitation has increased since about 1985. The trend in the SAL was decreasing pressure until about 1960 followed by increasing pressure, which paralleled the increasing drought in the Sahel. The increasing trend in SAL pressure terminated in the 1980s, and it has registered a small decrease in pressure since then, paralleling the recovery in Sahel precipitation. It thus appears that during the period from 1960 to 1985 , when the Sahel experienced a worsening drought, the long-term trends in 


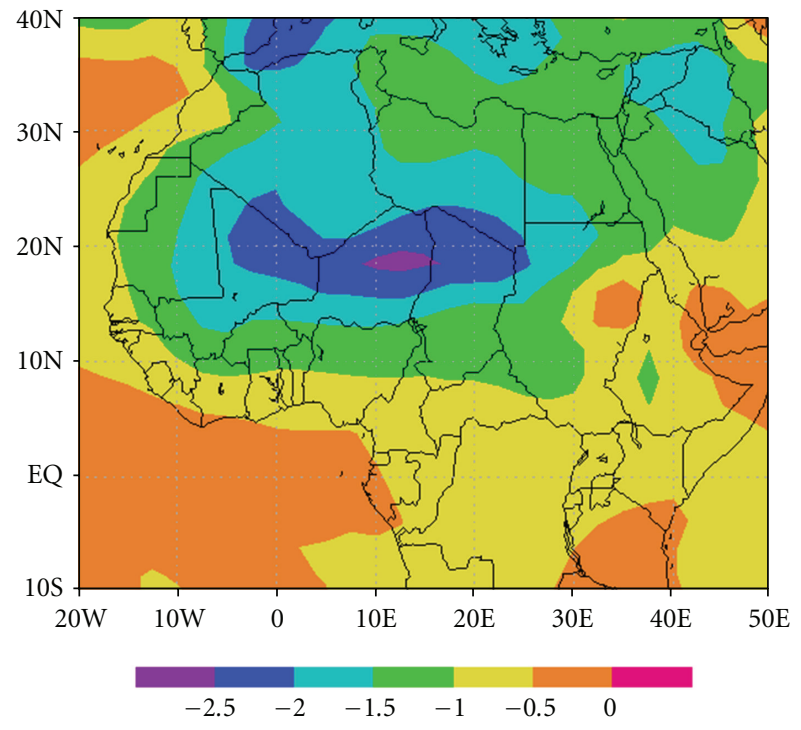

(a)
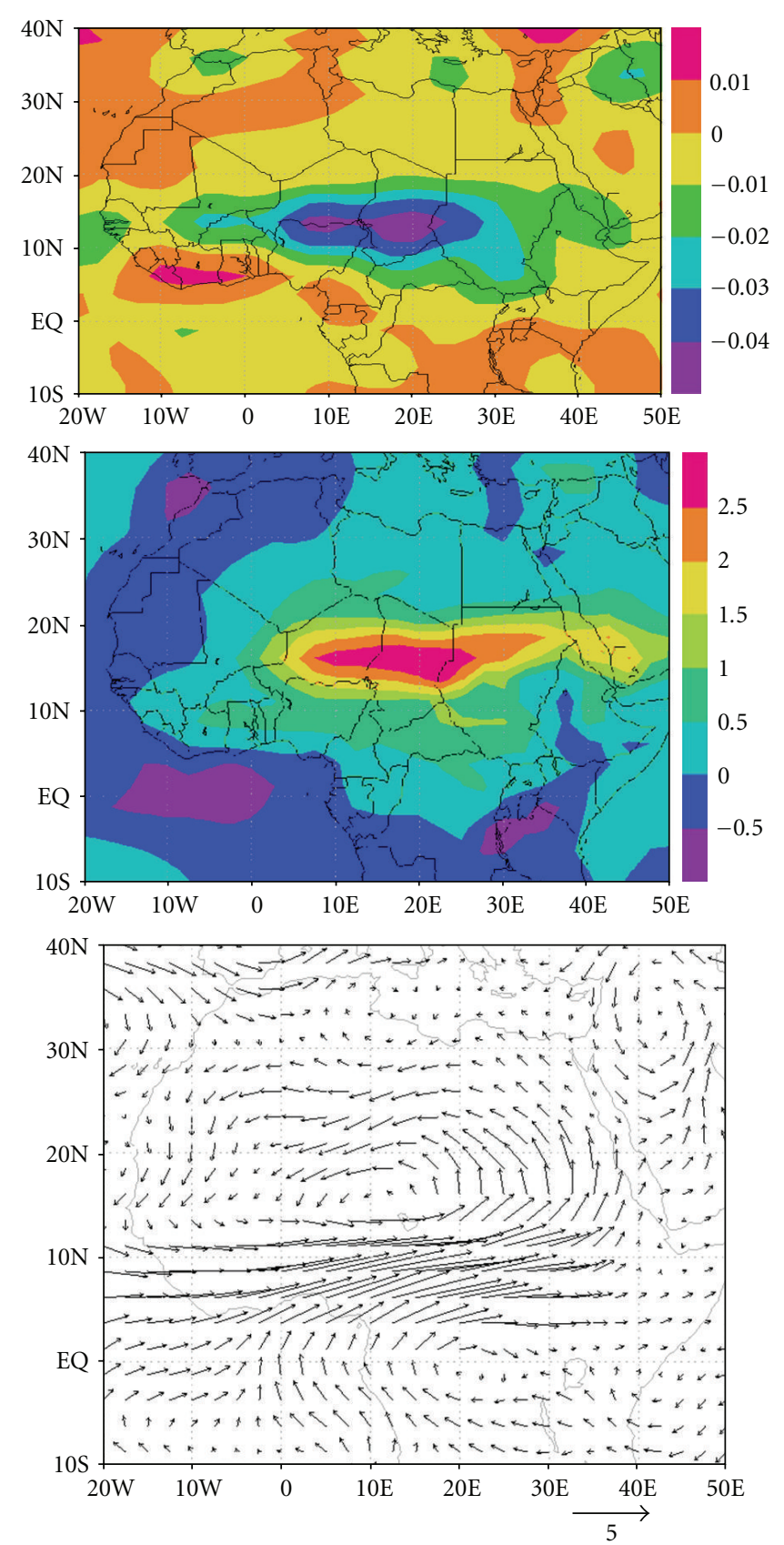

(b)

FIgURE 4: (a) Difference of SLP composites in hPa. Average over 10 years for AZH most westward minus average over 10 years for AZH most eastward. (b) Differences of AZH longitude composites for $\omega$ in $\mathrm{Pa} \mathrm{s}^{-1}$ (top), specific humidity in $\mathrm{g} \mathrm{kg}^{-1}$ (middle), and horizontal wind field in $\mathrm{m} \mathrm{s}^{-1}$ (bottom).

both SAL pressure and AZH longitude were supporting dry conditions in this region. The drought has partially ameliorated since the mid 1980s because both the AZH longitude and SAL pressure have changed trends since that time. Another interesting feature in Figure 3(a) is the lag of about 3 years between the trends in AZH and precipitation. The correlation between the two series at zero lag is -0.71 , and it is -0.80 with a lag of 3 years. There are other significant correlations at several lags between the COA and Sahel precipitation. This opens avenues for predicting the
Sahel precipitation using the COA indices as a basis, a topic we will explore in a separate paper.

To investigate the interannual variability, we define the anomaly $x^{\prime}$ of the variable $x$ for year $j$ as $x_{j}^{\prime}=x_{j}-$ $\langle x\rangle_{j}$, where $x_{j}$ is the value of $x$ in year $j$, and $\langle x\rangle_{j}$ is the 5-year moving average of $x$ for year $j$. The correlation between Sahel precipitation anomalies and the SAL pressure anomalies is -0.54 (time series shown in Figure 3(b)), and the correlation between precipitation anomalies and $\mathrm{AZH}$ longitude is -0.22 . The latter is not significant at 


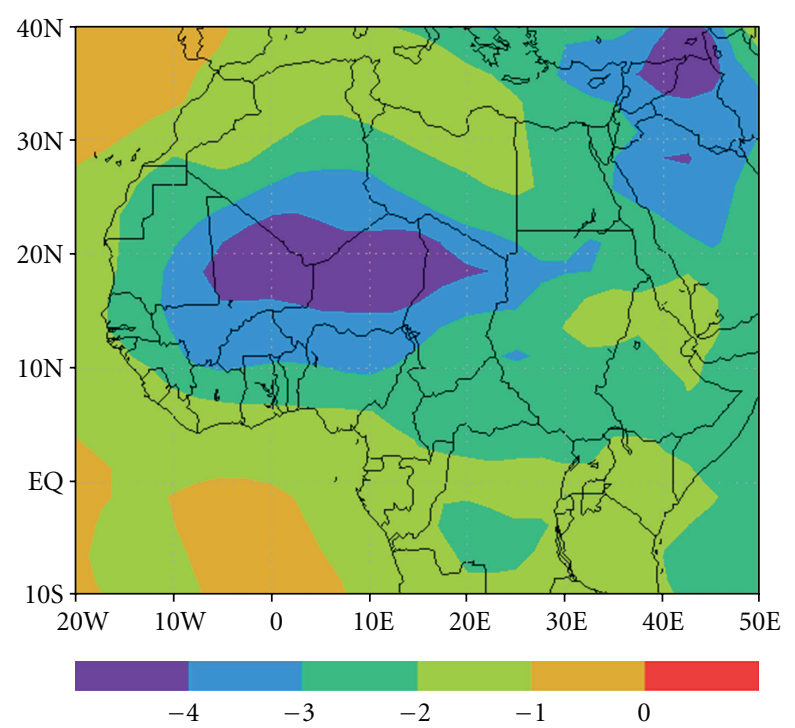

(a)
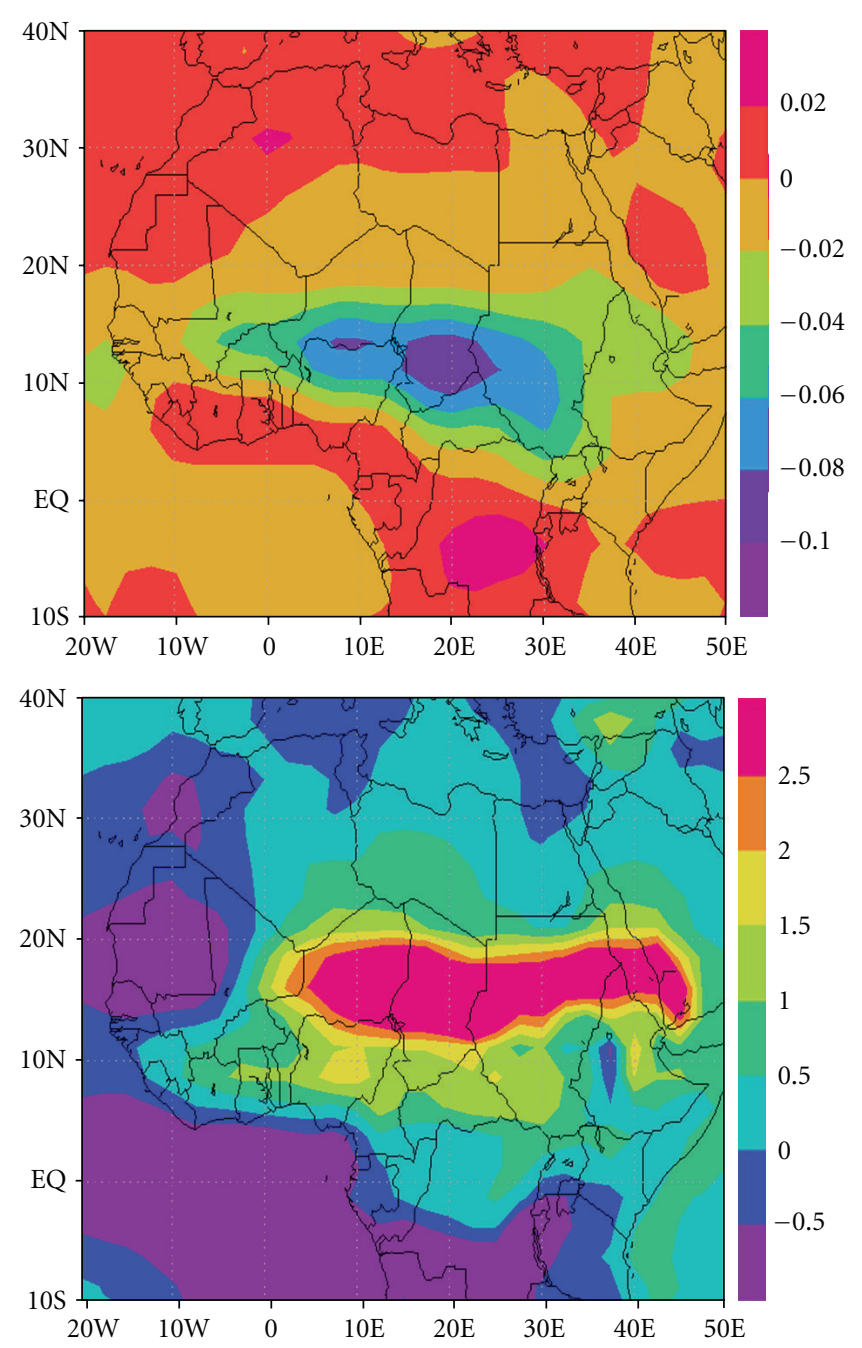

(b)

FIgURE 5: (a) Differences of SLP composites in hPa. Average over 10 years with SAL lowest pressure minus average over 10 years with SAL highest pressure. (b) Differences of SAL pressure composites at $850 \mathrm{hPa}$ for $\omega$ in $\mathrm{Pa} \mathrm{s}^{-1}$ (top), specific humidity in $\mathrm{g} \mathrm{kg}^{-1}$ (bottom).

the 5\% level. We conclude that SAL pressure significantly impacts both the trend and interannual variations of Sahel precipitation, whereas AZH longitude only impacts the longterm trend.

3.3. Composite Analysis. From the analysis above we infer that westward migration of the Azores High and decrease in the pressure of the South Asia Low correspond to increases in Sahel precipitation, and vice versa. To shed light on possible underlying physical mechanisms of the existing correlations, we constructed composite maps of meteorological variables using the NCEP reanalysis data. We averaged over the 10 years when the AZH longitude was most westward and most eastward and examined the difference of these averages, which corresponds to enhanced precipitation over the Sahel. We also performed an analogous analysis for SAL pressure. The years when the JAS average of AZH was most westward are 1999, 1956, 1950, 1960, 1994, 1964, 1967, 1952, 1951, and 2001. The JAS average of AZH was most eastward in 1995,
1987, 1948, 1971, 1990, 1979, 1969, 1997, 1978, and 1981. The years of lowest JAS SAL pressure are 1961, 1958, 1959, $1962,1954,1960,1964,1963,1955$, and 1956. The years of highest JAS SAL pressure are 2004, 1980, 1982, 1993, 1992, 1987, 1979, 2002, 1986, and 1997.

3.3.1. Influence of the Azores High. Figure 4(a) shows the difference in SLP over North Africa and regions to the north and west for the AZH composites. While it is to be expected that westward shifts in this high-pressure system result in low pressure anomalies over north Africa and western Europe, a surprising feature in Figure 4(a) is the localized low pressure anomaly of the order of 2 to $3 \mathrm{hPa}$ situated over the Sahel region. This pressure distribution results in a convergence zone over the Sahel, as indicated by diagnoses of vertical velocity, specific humidity, and vector winds at $850 \mathrm{hPa}$ shown in Figure 4(b). The difference wind vector displays a band from $5^{\circ} \mathrm{N}$ to $15^{\circ} \mathrm{N}$ directed from the Atlantic Ocean towards the East, indicating that westward shifts of 


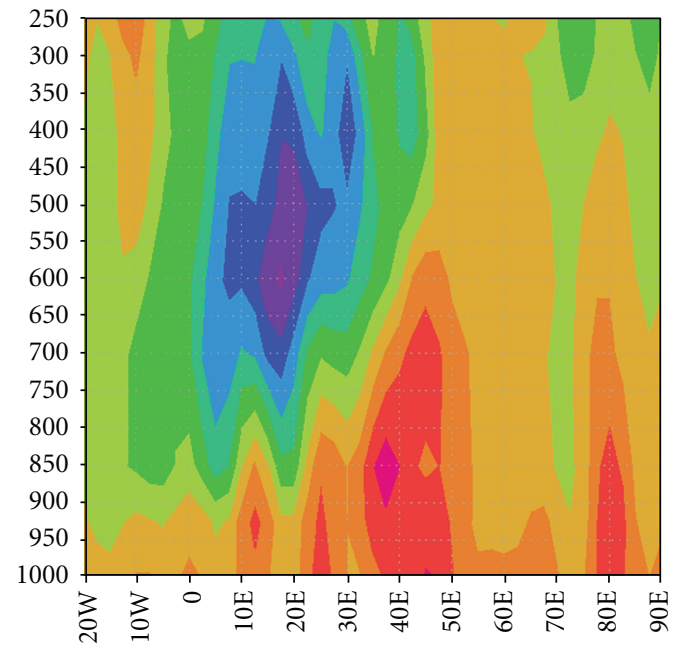

(a)

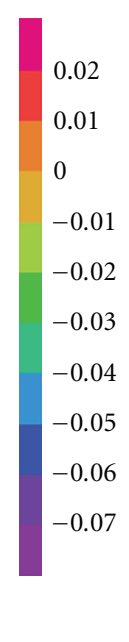

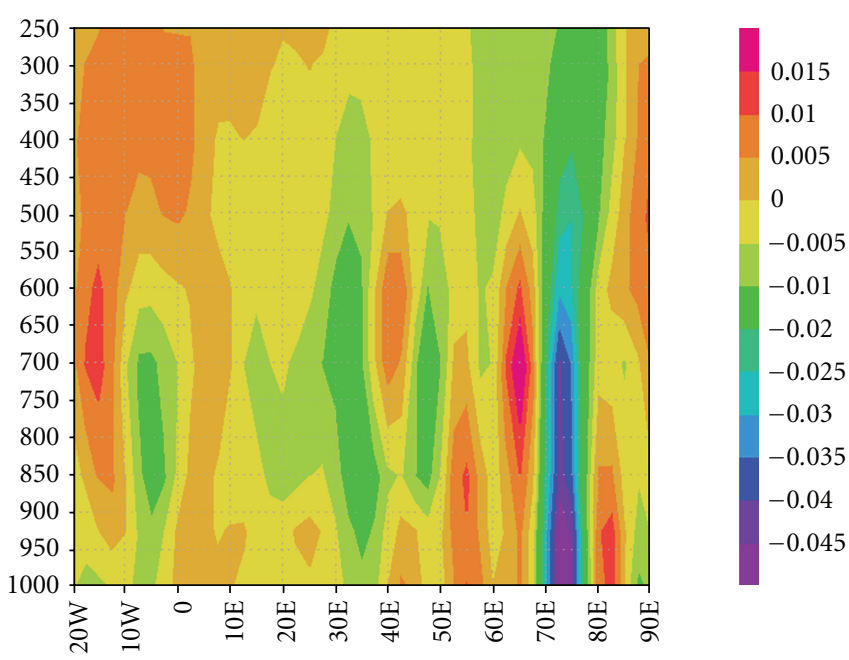

(b)

Figure 6: (a) Vertical cross-section differences for $\omega$-composites in $\mathrm{Pa} \mathrm{s}^{-1}$ averaged over the latitude band of $10^{\circ} \mathrm{N}-20^{\circ} \mathrm{N}$. Average over 10 years with SAL lowest pressure minus average over 10 years with SAL highest pressure. (b) Vertical cross section differences for $\omega$-composites in $\mathrm{Pa} \mathrm{s}^{-1}$ averaged over the latitude band of $20^{\circ} \mathrm{N}-35^{\circ} \mathrm{N}$. Average over 10 years with SAL lowest pressure minus average over 10 years with SAL highest pressure.

the AZH allow moisture transport from the Atlantic into the Sahel. The composite difference for specific humidity supports this finding with a maximum that peaks over the Sahel region, and the convergence results in a pronounced maximum in upward vertical velocities over the Sahel. Ward [22] observed that atmospheric pressure in the subtropical Atlantic is related to Sahel rainfall variation. A key distinction in our results is that it is the longitudinal displacements of the Azores High, and not its pressure fluctuations, that are related to Sahel precipitation.

The Azores High is located to the west of North Africa and this configuration is similar to that of the Indian Ocean High with respect to western Australia. It has been shown that east-west shifts in the position of the Indian Ocean High significantly influence rainfall in southwestern Australia where a multidecadal drought is in progress [12]. Thus, there are similarities between the relationships between the longitudinal displacements of the two subtropical highs and drought in the continents to their east.

\subsubsection{Influence of the South Asia Low. Figure 5(a) shows} the composite difference in SLP over North Africa and the adjacent regions between the years when the SAL has the lowest pressure and the years with the highest pressure. A low-pressure anomaly over the Sahel and the Sahara is noticeable. The observed anomaly pattern (Figure 5(a)) illustrates the far reaching influence of changes in the SAL on summer climate with SLP anomalies of $1 \mathrm{hPa}$ or more up to the eastern Atlantic, and anomalies of the order of $3 \mathrm{hPa}$ over large areas of Africa and the Middle East. Again, diagnoses of the vertical wind and specific humidity corroborate the formation of an anomalous convergence zone over the Sahel/Sahara region as shown in Figure 5(b).

Using a 3-dimensional hydrostatic primitive equation model, Rodwell and Hoskins [23] have investigated the relationship between the south Asia monsoon and the circulation over the Sahara. Their model suggests that diabatic heating during the monsoon induces a westward propagating Rossby wave, which results in adiabatic descent over the eastern Sahara and the Mediterranean.

Note that this does not imply that the strength of South Asia monsoon is related to the Azores High pressure system, which encompasses large sections over the Atlantic besides the Mediterranean and North Africa. As mentioned before, the South Asia Low pressure and the Azores High longitude position, as calculated by (1) and (2), are not correlated with each other. However, in Figure 5(a) for the SLP composite differences between the summers in which the South Asia Low was the deepest and the summers in which it was the shallowest, we see the anomalous pressures rising north of the Sahel zone to the Mediterranean, which indicates greater descent in this region when the South Asia Low is deeper. This observation is consistent with the model results presented in [23]. Figures 6(a) and 6(b) show the composite difference of vertical velocity for a longitudinal cross-section averaged over the Sahel latitudes $\left(10^{\circ} \mathrm{N}-20^{\circ} \mathrm{N}\right)$. For the case of deeper SAL we see rising motion from $10^{\circ} \mathrm{W}$ to $50^{\circ} \mathrm{E}$ in the lower troposphere. In the analogous composite difference for the Sahara region $\left(20^{\circ} \mathrm{N}-35^{\circ} \mathrm{N}\right)$ we find a strong descent over most of the troposphere.

This suggests the following scenario: a stronger South Asia Low related to a stronger monsoon induces descending air over the Sahara and the Mediterranean, resulting in an anomalous southward flow over North Africa and convergence over the Sahel.

\section{Conclusions}

This paper has presented evidence that July-AugustSeptember precipitation in the Sahel is related to the 
east-west displacements of the Azores High and to the pressure fluctuations of the South Asia Low. A regression equation was developed that could explain 50 percent of the variance of the Sahel precipitation over 1948-1998. This result supports the basic meteorological picture that precipitation occurs when clouds are present and the local atmosphere is unstable. The results presented suggest these atmospheric conditions are strongly influenced over the Sahel by changes in the Azores High position and the South Asia Low pressure. The SOI is also related to the interannual variability of Sahel precipitation but its contribution is less significant than that of the SAL pressure.

The results suggest that a GCM can give a physically correct simulation of Sahel rainfall trends and interannual variability if it can adequately represent the dynamics of the $\mathrm{AZH}$ and the SAL pressure centers in terms of both their pressures and locations. Since the AZH is located over the ocean it is likely that interaction between the atmosphere and the ocean plays an important role in its variation. The SAL is primarily a land-based phenomenon, and interaction with the ocean is likely to be less important to its simulation than for the AZH.

\section{References}

[1] M. B. K. Darkoh, "The nature, causes and consequences of desertification in the drylands of Africa," Land Degradation and Development, vol. 9, no. 1, pp. 1-20, 1998.

[2] N. Riemer, O. M. Doherty, and S. Hameed, "On the variability of African dust transport across the Atlantic," Geophysical Research Letters, vol. 33, Article ID L13814, 4 pages, 2006.

[3] O. M. Doherty, N. Riemer, and S. Hameed, "Saharan mineral dust transport into the Caribbean: observed atmospheric controls and trends," Journal of Geophysical Research D, vol. 113, no. 7, Article ID D07211, 2008.

[4] J. K. Angell and J. Korshover, "Quasi-biennial and long-term fluctuations in the centers of action," Monthly Weather Review, vol. 102, no. 10, pp. 669-678, 1974.

[5] J. G. Charney, "Dynamics of deserts and drought in the Sahel," Quarterly Journal of the Royal Meteorological Society, vol. 101, no. 428, pp. 193-202, 1975.

[6] W. M. Cunnington and P. R. Rowntree, "Simulations of the Saharan atmosphere-dependence on moisture and albedo," Quarterly Journal of the Royal Meteorological Society, vol. 112, no. 474, pp. 971-999, 1986.

[7] Y. C. Sud and W. E. Smith, "The influence of surface roughness of deserts on the July circulation-a numerical study," Boundary-Layer Meteorology, vol. 33, no. 1, pp. 15-49, 1985.

[8] K. M. Lau, S. S. P. Shen, K.-M. Kim, and H. Wang, "A multimodel study of the twentieth-century simulations of Sahel drought from the 1970s to 1990s," Journal of Geophysical Research D, vol. 111, no. 7, Article ID D07111, 2006.

[9] K. H. Cook and E. K. Vizy, "Coupled model simulations of the West African monsoon system: twentieth- and twenty-firstcentury simulations," Journal of Climate, vol. 19, no. 15, pp. 3681-3703, 2006.

[10] M. K. Tippett, "Filtering of GCM simulated Sahel precipitation," Geophysical Research Letters, vol. 33, no. 1, Article ID L01804, 2006.

[11] C. G. Rossby et al., "Relation between variations in the intensity of the zonal circulation of the atmosphere and the displacement of the semi-permanent centers of actions," Journal of Marine Research, vol. 2, no. 1, pp. 38-55, 1939.

[12] S. Hameed, M. J. Iqbal, S. Rehman, and D. Collins, "Impact of the Indian Ocean high pressure system on winter precipitation over western and Southwestern Australia," Australian Meterological and Oceanic Journal, vol. 61, no. 3, pp. 159-170, 2011.

[13] S. Hameed, W. Shi, J. Boyle, and B. Santer, "Investigation of the centers of action in the North Atlantic and North Pacific in the ECHAM AMIP simulation," in Proceedings of the 1st International AMIP Scientific Conference, p. 221, Monterey, Calif, USA, 1995, WCRP 92.

[14] K. E. Trenberth and D. A. Paolino, "The Northern Hemisphere sea-level pressure data set: trends, errors and discontinuities," Monthly Weather Review, vol. 108, no. 7, pp. 855-872, 1980.

[15] E. Kalnay, M. Kanamitsu, R. Kistler et al., "The NCEP/NCAR reanalysis 40-year project," Bulletin of the American Meteorological Society, vol. 77, pp. 427-471, 1996.

[16] M. Hulme, "Validation of large-scale precipitation fields in general circulation models," in Global Precipitations and Climate Change, M. Desbois and F. Desalmand, Eds., NATO ASI Series, pp. 387-406, Springer, Berlin, Germany, 1994.

[17] M. Hulme, T. J. Osborn, and T. C. Johns, "Precipitation sensitivity to global warming: comparison of observations with HadCM2 simulations," Geophysical Research Letters, vol. 25, no. 17, pp. 3379-3382, 1998.

[18] S. E. Nicholson, "The nature of rainfall fluctuations in subtropical West Africa (Guinea Sahel Soudan)," Monthly Weather Review, vol. 108, no. 4, pp. 473-487, 1980.

[19] C. K. Folland, J. Owen, M. N. Ward, and A. Colman, "Prediction of seasonal rainfall in the Sahel region using empirical and dynamical methods," Journal of Forecasting, vol. 10, no. 1-2, pp. 21-56, 1991.

[20] D. S. Wilks, Statistical Methods in the Atmospheric Sciences, Academic Press, New York, NY, USA, 2011.

[21] B. Wang, The Asian Monsoon, Springer Praxis Books, 2006.

[22] M. N. Ward, "Diagnosis and short-lead time prediction of summer rainfall in tropical North Africa at interannual and multidecadal timescales," Journal of Climate, vol. 11, no. 12, pp. 3167-3191, 1998.

[23] M. J. Rodwell and B. J. Hoskins, "Monsoons and the dynamics of deserts," Quarterly Journal of the Royal Meteorological Society, vol. 122, no. 534, pp. 1385-1404, 1996. 

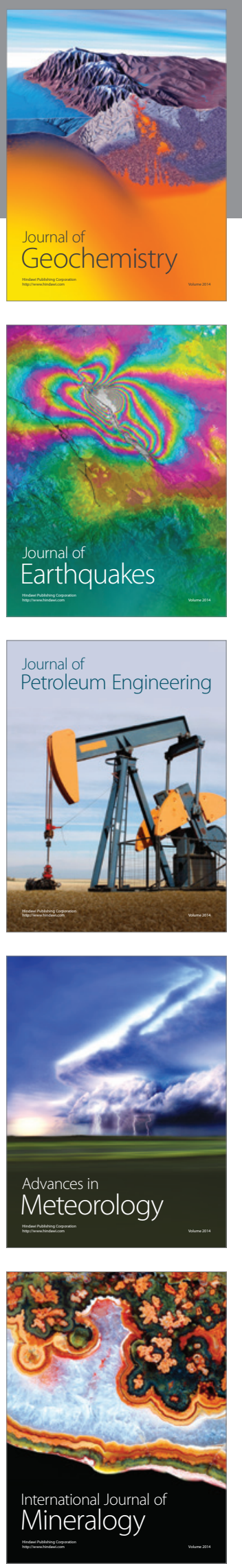
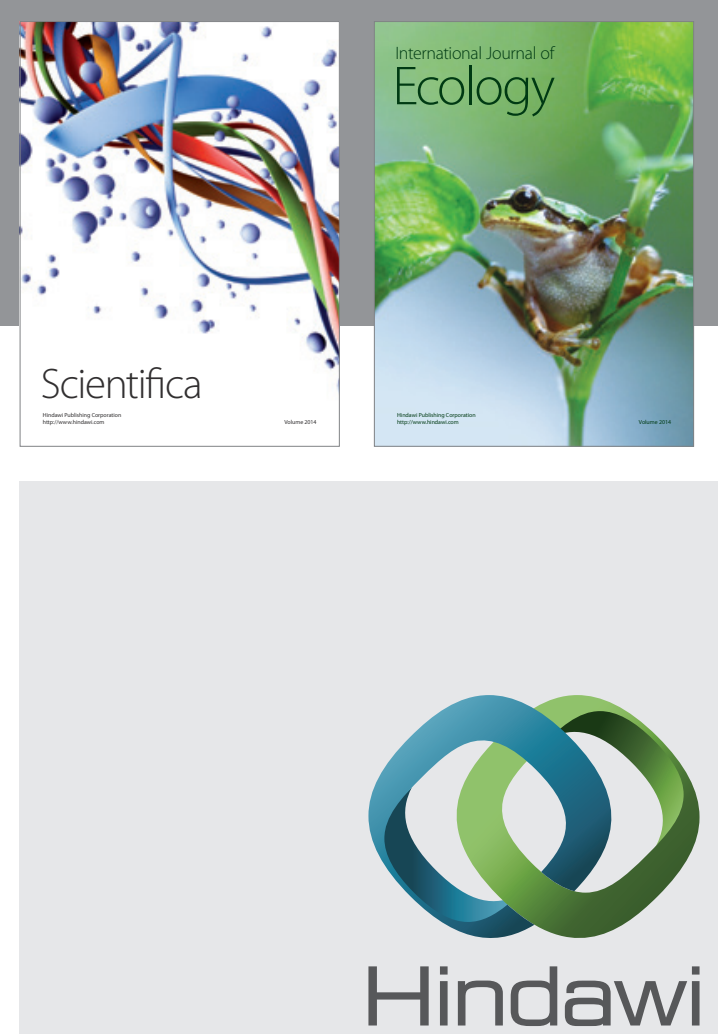

Submit your manuscripts at http://www.hindawi.com
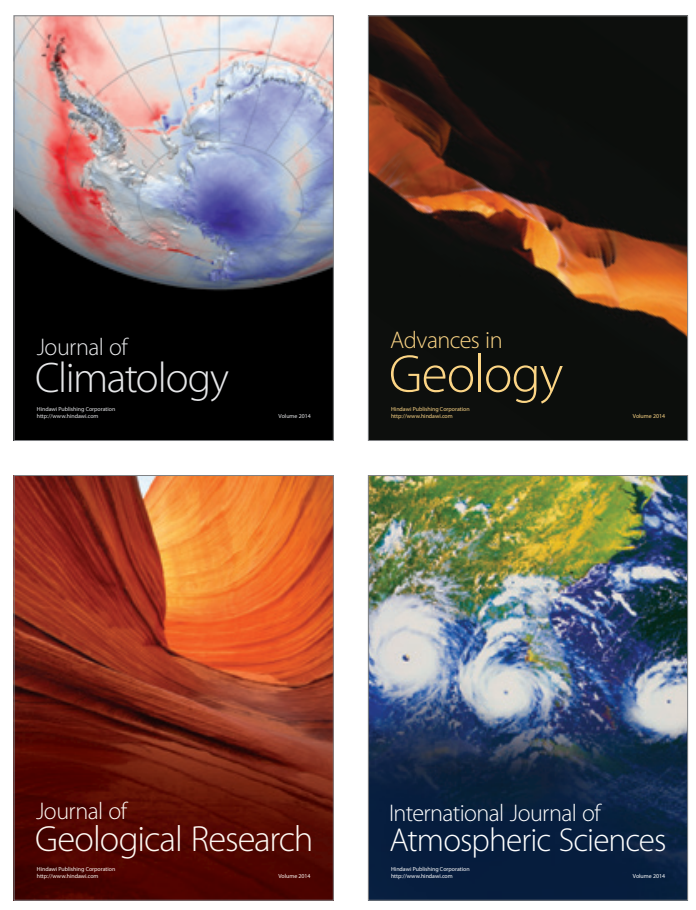
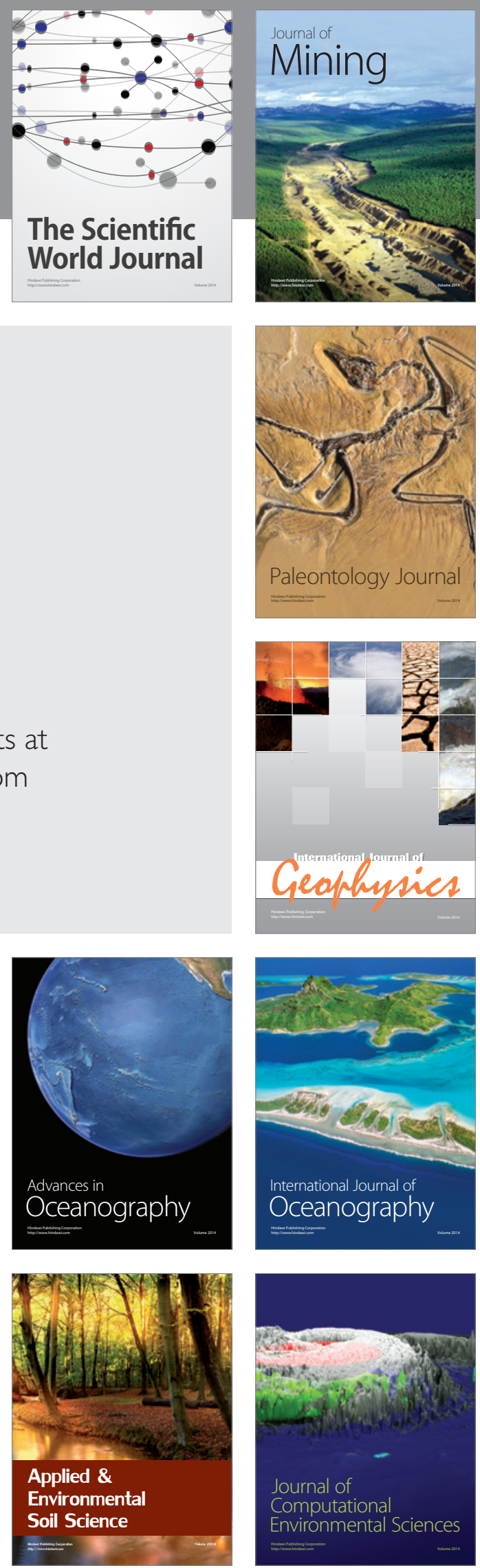